Case Report

\title{
Tumour mimicking in musculoskeletal system in Surabaya: A case series
}

\author{
Bayu Antara Hadi ${ }^{*}$, Mouli Edward ${ }^{2}$ \\ 1) Resident of Orthopaedic and Traumatology Department, Medical Faculty of Airlangga University, Dr. Soetomo \\ Hospital, Surabaya, Indonesia \\ 2) Staff of Orthopaedic and Traumatology Department, Medical Faculty of Airlangga University, Dr. Soetomo \\ Hospital, Surabaya, Indonesia
}

\begin{tabular}{ll}
\multicolumn{1}{c}{ A R T I C L E } & I N F O \\
\hline Submitted & : November 2019 \\
Accepted & : December 2019 \\
Published & : January 2020 \\
\hline
\end{tabular}

Keywords:

Tumour mimicking, osteosarcoma, chondroma, malignancy

\section{*Correspondence:}

bayuantarahadi@gmail.com

\begin{abstract}
Musculoskeletal tumors are potential causes of heavy morbidity and economic burdens for patients. There are often cases suspected as musculoskeletal tumors based on a specific diagnostic modality because of overlapping features upon physical examination or a tumor-like appearance from the radiological examination, the more reason for triple diagnosis to be performed for an exact diagnosis. We report 5 cases of fractures tumor-mimicking lesions. The First patient, a patient with MRI revealing a primary malignant bone tumor, but with plain thorax x-ray and FNAB, the diagnosis was tuberculosis arthritis of the elbow. The second patient shows metastatic proses with plain radiographic, but from open biopsy, the diagnoses fall to chronic osteomyelitis. The third patient had a history of papillary carcinoma thyroid with pathological fracture of proximal of the left femur, but the biopsy shows a hypercalcemic state. The fourth patient, had mass size $20 \times 15 \mathrm{~cm}$ at the thigh, but the biopsy shows Non-Specific Chronic Osteomyelitis. The fifth patient with progressive swelling of the left knee for one year, 10x10 cm in size, the biopsy showed no sign of malignancy but tuberculosis of left distal femur. In conclusion, standard comprehensive diagnosis steps consisting of clinical history, imaging, laboratory and histopathological examinations are crucial to differentiate tumor-mimicking lesions from neoplasms, thus ensuring proper treatment.
\end{abstract}




\section{INTRODUCTION}

The reactive lesion from the bone and the soft tissue found during the histological examination, have a cellular atypical cytological figure, similar in appearance with various nucleus and light hyperchromatic, and mitotic activity (Salter RB, 1999). Reactive lesions from the bone and the periosteum forming the bone and cartilage matrix often confused with osteosarcoma and chondrosarcoma (Solomon L, Warwick D, 2010). The cytomorphology of the bone, the uniform figure of the cell, and the absence of atypical mitosis may aid in identifying the reactivity of the lesion (Gersch, Lombardo, McGovern, \& Hadjiargyrou, 2005). The relation between the clinical and radiological appearance is paramount in order to avoid the wrong classification of the tumor (Hoch \& Montag, 2011) because the reactive lesion is often present in the area where the osteosarcoma and chondrosarcoma are rarely found (i.e., the arm) and showing signs of malignancy (Kim, Park, Ryu, Jin, \& Park, n.d.).

A retrospective observational study in RSUD Dr. Soetomo, from the data in the year 20112014, there are 460 new cases suspected as a musculoskeletal tumor, previously evaluated clinically, radiological, and pathologically, which was then discussed by the tumor board. Of 460 cases, 277 are males, 183 are females. Final diagnosis: 193 benign cases (41\%), 251 malignant (54\%), 16 infected (3\%), 4 metabolic cases $(0.8 \%), 8$ inflammation $(1,6 \%), 1$ osteolysis $(0.2 \%)$ and 1 bone necrosis $(0,2 \%)$. There are 30 cases of tumor mimicking $(6.5 \%)$.

Musculoskeletal tumor cases cost a sum amount of money, and as it progresses, and not so rarely worsen, the cost would inflate to unaffordable proportion to the patient (Ward WG, Corey RM, Watkins-Castillo SI, 2014).
Primary bone tumors are rare, thus the rare opportunity as an experience. According to the radiologic imaging and the histopathology result, and the severe consequence of the wrong surgical procedure, the proper management of the bone tumor is by a multidisciplinary approach (Madewell, Ragsdale, \& Sweet, 1981). Accurate diagnostic requires clinical, radiologic, and pathologic evaluation (Binesh, Sobhan, Moghadam, \& Akhavan, 2013).

\section{DESCRIPTION}

\section{Case 1}

A 52 years old male patient complained of pain in his right elbow for one year. The patient had a history of trauma seven years prior. From MRI, we found mass with 67,1 x 54,5 x 104,4cm also sunray appearance which suggested a primary malignant bone tumor (image 1). However, Radiology finding from elbow AP/ LAT 2 months after initial MRI suggested another disease (image 2), septic arthritis of Tuberculosis with osteomyelitis, and disuse osteopenia.

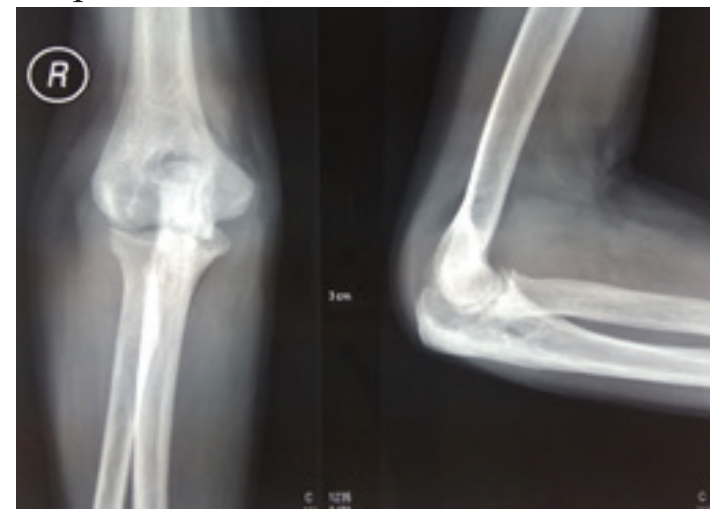

Image 1. Elbow AP/Lat, from plain radiographic, showing septic arthritis.

We diagnosed him as a septic arthritis of tuberculosis. The histopathological examination from his elbow showed granulomatous inflammation, which suggested tuberculosis (image 3). Even though the laboratory finding not support this diagnosis with Leucocyte 6.27, CRP 2,3, Ca 5, Phosphate 4.2. The therapy we 
give for this patient is debridement, mediallateral ligament reconstruction collateral ligament of the elbow with fascia lata, and antituberculosis drug (image 4).

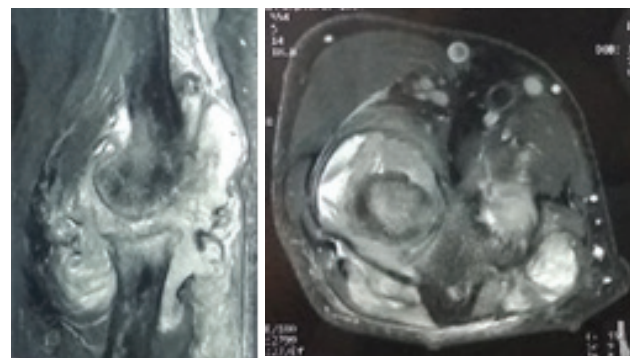

Image 2. MRI Elbow with contrast. The sun ray appearance suggesting to primary bone tumor malignant

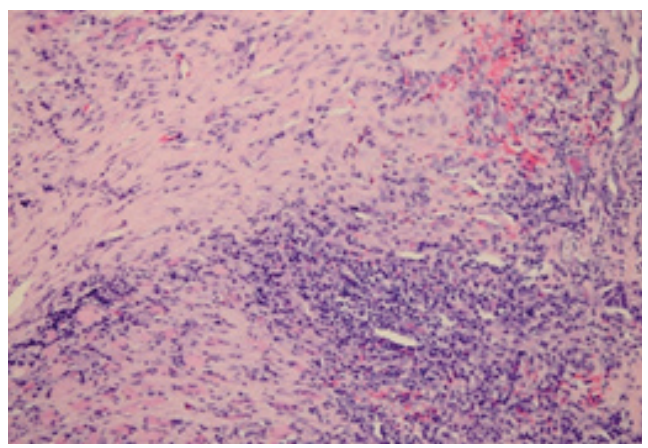

Image 3. PA Examination. The histopathological examination from his elbow showed granulomatic inflamation which suggested tubrculosis
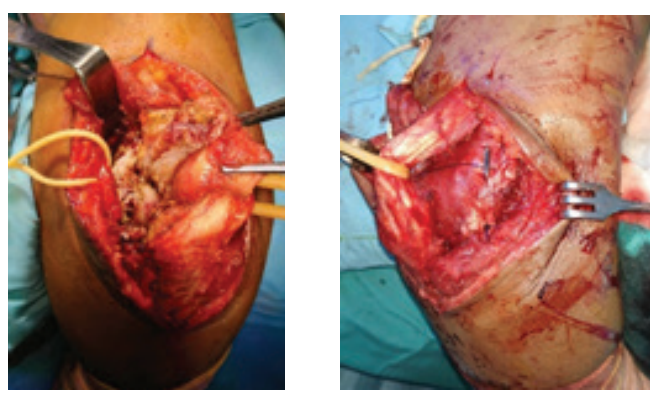

Image 4. Debridement and Ligament reconstruction

\section{Case 2}

The second patient, A 53 years old male patient complained of pain in his right thigh. The patient had a history of fell two weeks prior at the bathroom but no history
Of lump anywhere in the patient body. From the plain radiographic, there was found a lytic lesion at medulla diaphysis of $1 / 3$ distal of the right femur (image 5), which suggested two differential diagnosis: a metastatic and an infection process. After an MRI examination was held, we can narrow down the diagnostic to osteomyelitis because there is no sign of metastatic proses (image 6).

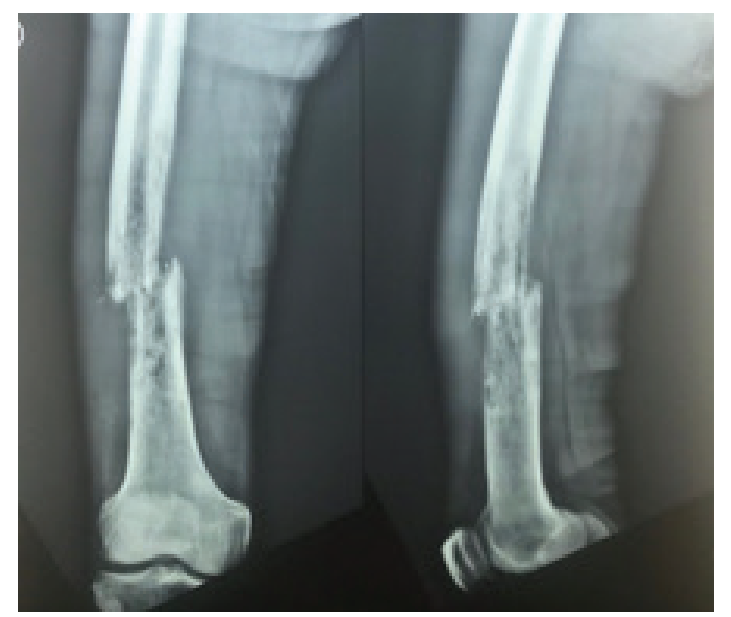

Image 5. Right Femur x-ray: showing lytic lesion with pathological fracture

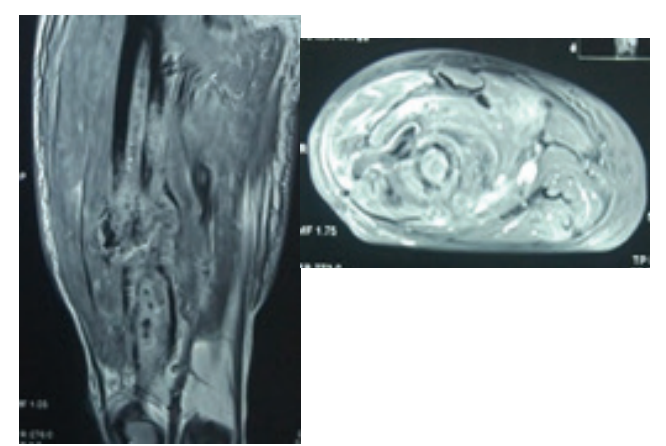

Image 6. MRI of femur of the 2nd patient.

This finding still needs to be confirmed to give the patient a proper therapy. From FNAB, we found there is no sign of malignancy, and with core biopsy, the definitive diagnosis was found necrotic with chronic suppurative inflammation with non-specific inflammation. The patient then treated with debridement sequestrectomy, fill the gap bone of femur with bone cement with masquelet technique, gentamycin beads and external fixation (image 7). 


\section{QANUN MEDIKA Vol 4 No 1 JANUARY 2020}

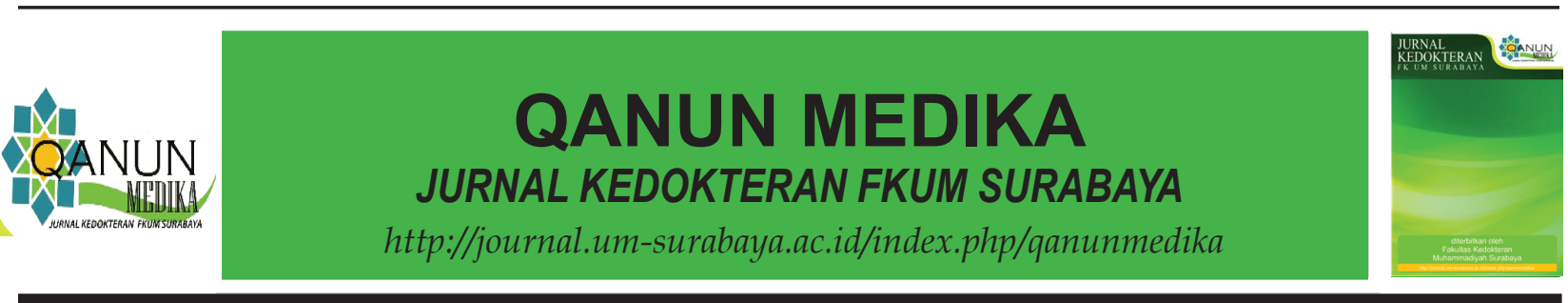

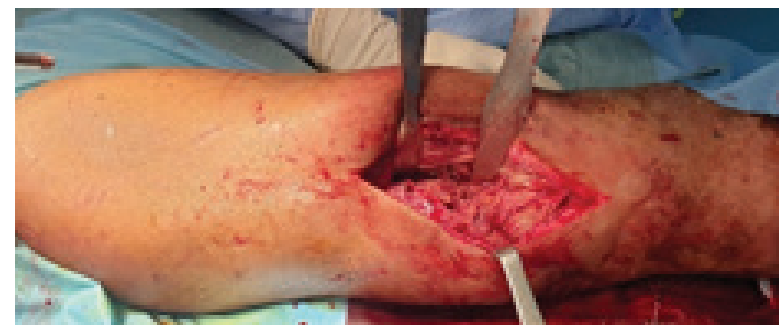

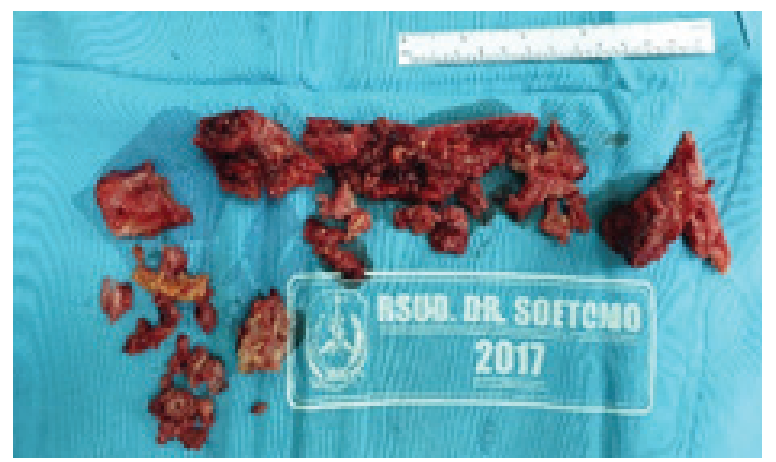

Image 7. (Top) Durante Operation, (Bottom) necrotic with chronic suppurative inflammation with nonspecific inflammation

\section{Case 3}

A 60 years old male patient complained of pain in his left hip for one year ago. The patient was unable to walk for three weeks before came to the hospital. The patient had a history of thyroidectomy surgery, and the histopathological examination from his thyroid post thyroidectomy surgery showed papillary carcinoma thyroid. From his laboratory, results showed BUN/SK 33/2.4, Ca 12.8, ALP 409, CRP 2.3, PSA 7.17, Bence-Jones protein (-), PTH 1256. X-ray of the left femur (Image $8 \mathrm{~b}$ ), pelvic (Image 8a), bone surveys (Image 9), CT scan of the left femur (Image 10) showed the lytic lesion

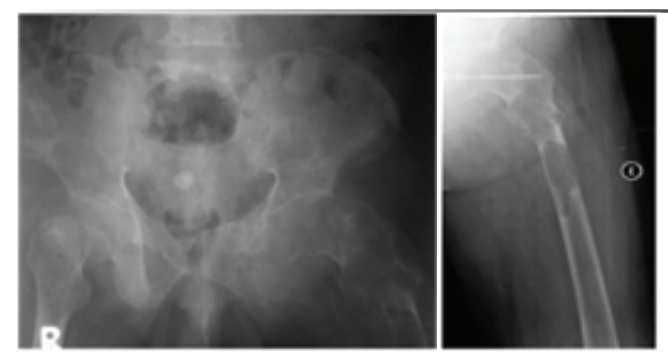

Image 8. a. Pelvic x-ray ; b. Left Femur X-ray, both a and $b$ showed pathological fracture of the left proximal femur

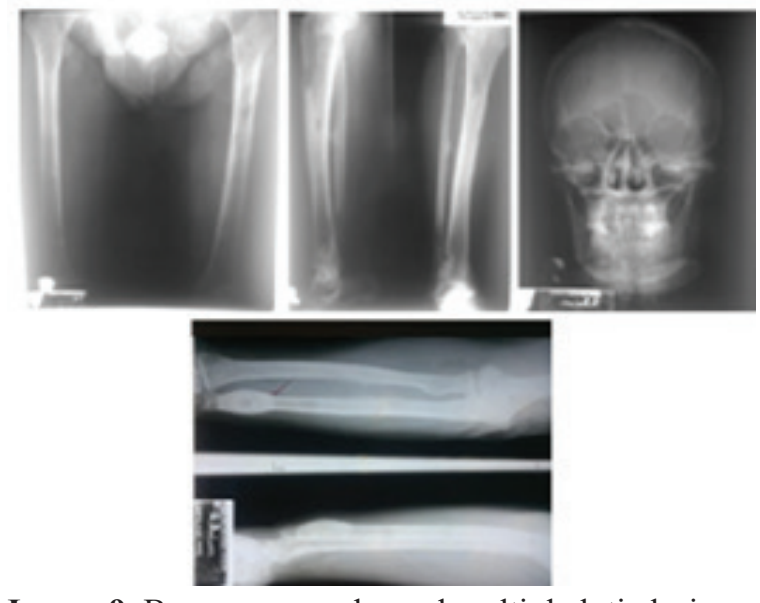

Image 9. Bone surveys showed multiple lytic lesions

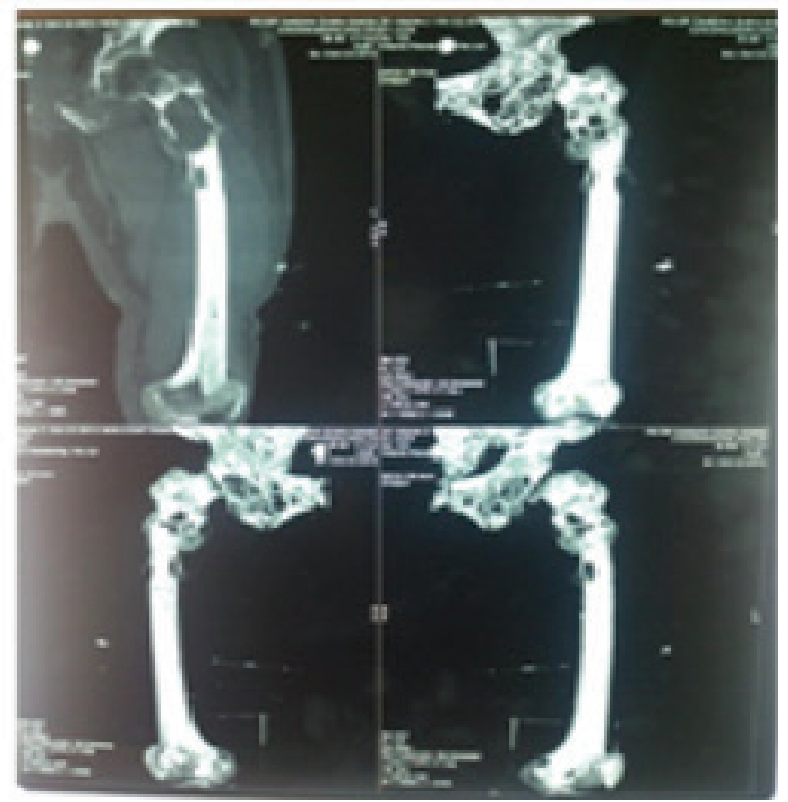

Image 10. CT scan of the left femur, showed the lytic lesions and the left proximal femur fractured

We diagnosed him as a pathological fracture of the proximal of the left femur with hyperparathyroid, and the therapy was Megaprosthesis of Left Hip. The histopathological examination of bone specimen (Image 11a) showed it was in the hypercalcemic state and no sign of neoplasm process. The evaluation of the left femur condition used the x-ray post mega prosthesis, (Image 11b) showing a good condition of the patient 


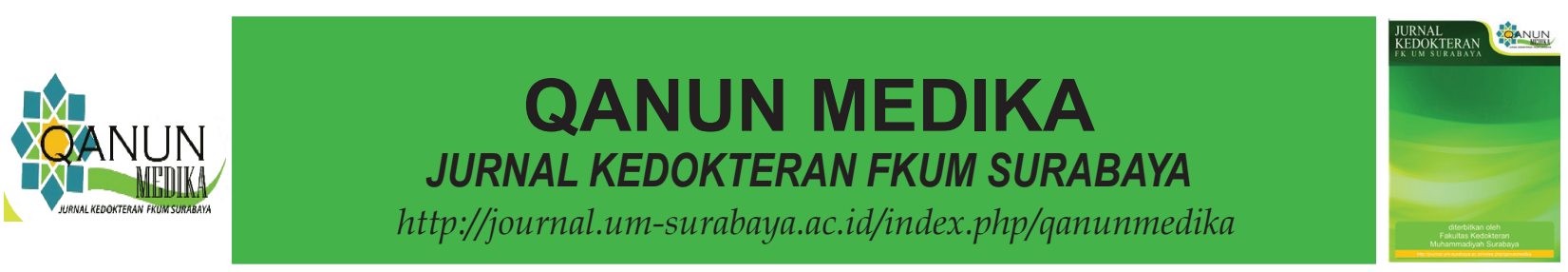

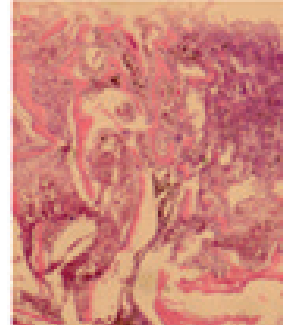
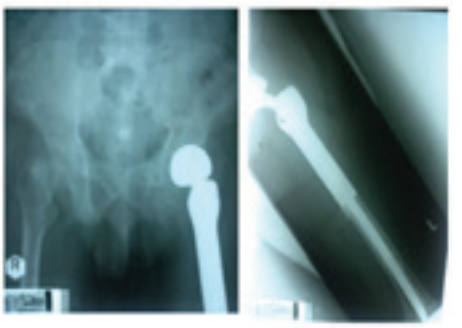

Image 11. Post Megaprosthesis of the left femur; (a.) Histopathology of the bone specimen; (b) pelvic X-Ray Post Megaprosthesis of the left femur for evaluation.

\section{Case 4}

A 19 years old male complained of swelling at his right thigh for four years ago, there were pain and warm temperature of the skin. From the physical examination of the right thigh, there was a mass size of $20 \times 15 \mathrm{~cm}$. There was tenderness, cystic, mobile warm, and smooth surfaces, also limited ROM due to the pain.

His Laboratory showed that $\mathrm{Hb}$ : 9,5, WBC 11.000, Plt 372.000, ESR 80, CRP 2.8, and Albumin 2.8. X-ray (Image 12) showed no deformity of the bone, while the MRI of the left knee (Image 13) showed bone abscess in the right distal femur and fluid collection in the suprapatellar region prefer to the inflammatory process. The histopathology of the right femur specimen showed Non-Specific Chronic Osteomyelitis (Image 14). Therefore, we diagnosed him with chronic osteomyelitis in his right femur region and gave them antibiotics for the treatment.
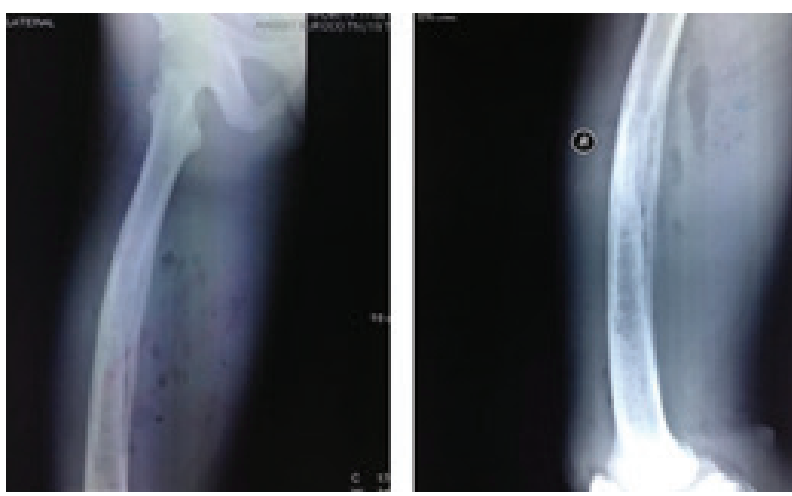

Image 12. X-ray of the right femur
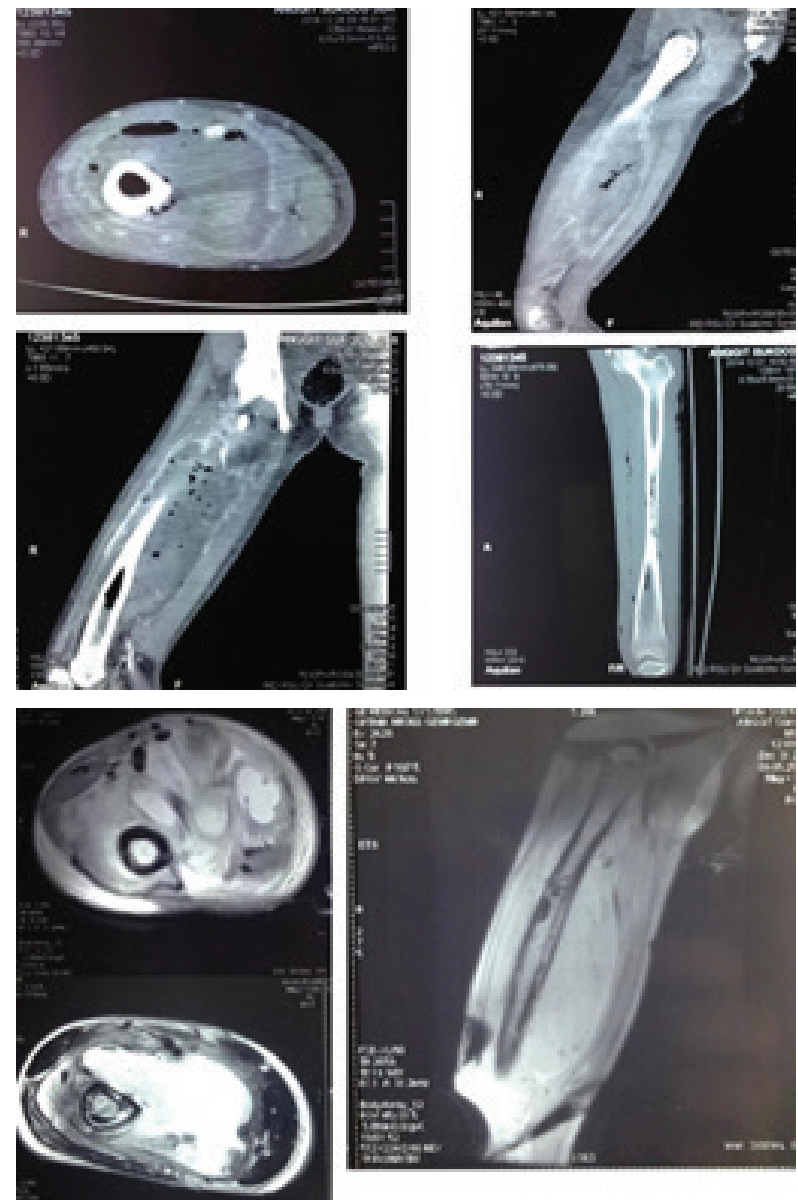

Image 13. MRI of the right femur

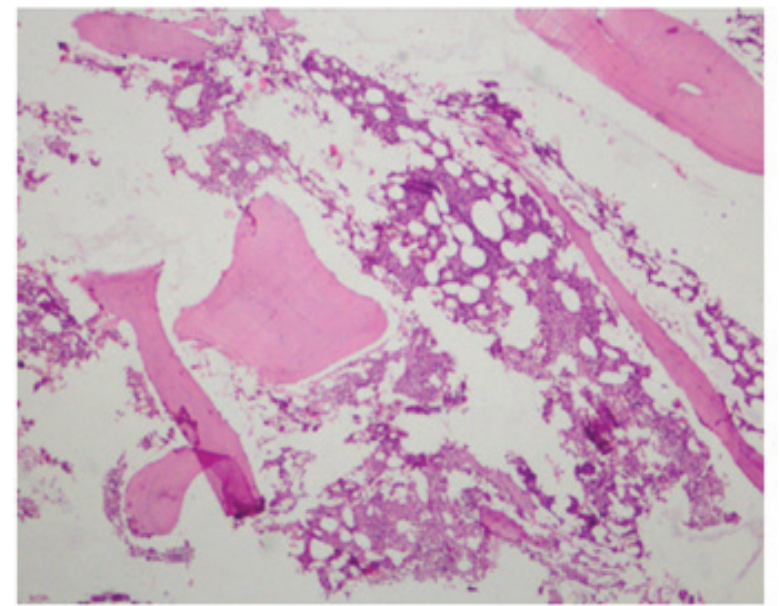

Image 14. Histopathological examination showed Chronic Osteomyelitis 


\section{QANUN MEDIKA \\ JURNAL KEDOKTERAN FKUM SURABAYA \\ http://journal.um-surabaya.ac.id/index.php/qanunmedika}

\section{Case 5}

A 15 years-old female complained of her swelling left knee for one year ago. The swelling was progressively bigger. The pain was felt especially when she was doing her knee movements. The physical examination of her left knee (Figure 15) was swelling 10x10 $\mathrm{cm}$. There was tenderness, solid consistency of the swelling mass, fixed, and smooth surface of the swelling mass.

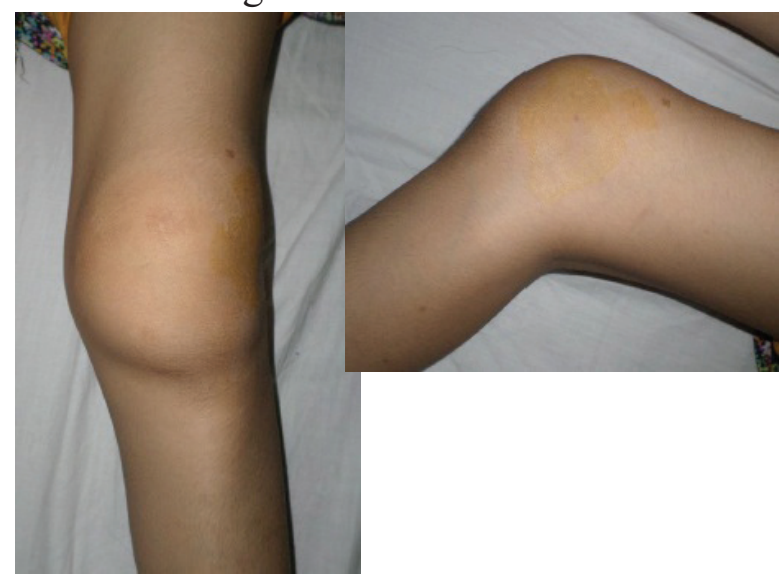

Image 15. Clinical examination of her left knee region showed swelling

The ROM was limited due to the pain. Laboratory results showed the elevation of the ESR $40-50 \mathrm{~mm}$, and others were in the normal limit. X-ray of the left femur (Image 16) showed there was no sign of deformity of the bone.

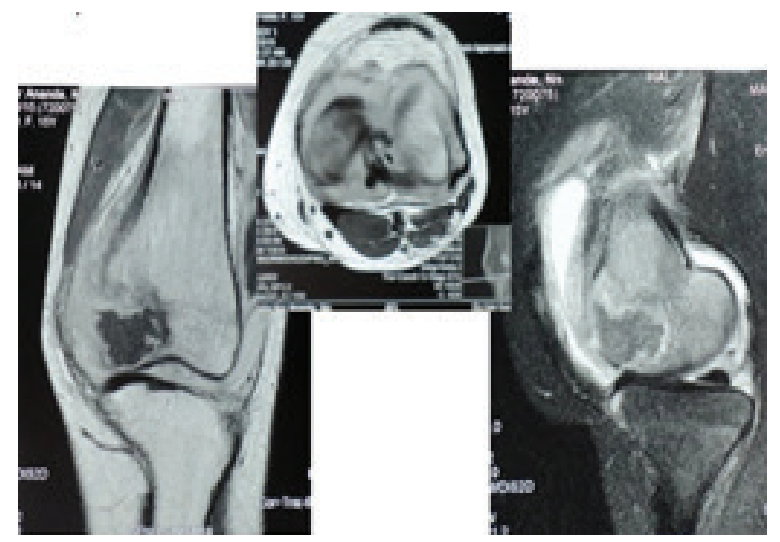

Image 16. MRI of the left knee of the patient showed bone abscess

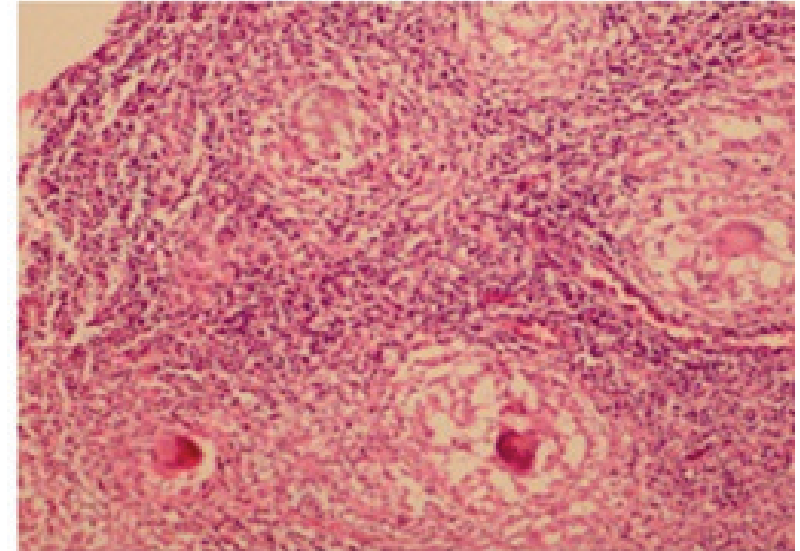

Image 17. The histopathological examination showed tuberculosis

\section{DISCUSSION}

From the first case, the MRI result was consistent with the primary malignant tumor indicating osteosarcoma. However, the plain x-ray of elbow showing signs of the specific infection process of septic arthritis of tuberculosis, hence by the histologically, the patient was not consistent with a primary bone tumor. With the result showing a specific inflammation process. Therefore we can conclude that in the first patient, even though the MRI result strongly suggested of primary malignant tumor, the other two modalities showing septic arthritis.

The second case, malignant tumor evident from plain femur x-ray obstructs the patient diagnostic. The signs are consistent with the metastatic process, the age, the lesion in lytic form. The infection process has yet to be ruled out. The bone survey showed a nonspecific chronic inflammatory process, with the periosteal reaction that could bring the diagnosis to malignancy. Osteomyelitis similar to a malignant bone tumor, both are having no specific signs. Defining the diagnosis from the two facts are paramount in deciding the exact clinical management. But with core biopsy, we could conclude that this patient does not have a malignancy but Non-specific chronic suppurative inflammation 
In the third case, the histopathological examination from his thyroid post thyroidectomy surgery showed papillary carcinoma thyroid, and it was in the hypercalcemic state and no sign of neoplasm process. The femur x-ray showed the lytic lesion and pathological fracture of the proximal left femur. The evaluation of the left femur condition used the x-ray post mega prosthesis showed an excellent condition of the patient.

In the fourth case, the x-ray showed no deformity of the bone, while the MRI of the left knee showed bone abscess in the right distal femur, and fluid collection in the suprapatellar region prefer to the inflammatory process. The histopathology of the right femur specimen showed non-Specific Chronic Osteomyelitis (Huang et al., 2013). Therefore, the patient diagnosed with chronic osteomyelitis in his right femur region and gave them antibiotics for the treatment.

In the fifth case, laboratory results showed the elevation of the ESR $40-50 \mathrm{~mm}$; others were in the normal limit. The MRI of the left knee showed that there was a bone abscess on the left distal femur and also a collection of fluid in the suprapatellar region suspected as inflammatory processes. The histopathological examination of the left knee specimen which showed that it was Tuberculosis of the left distal femur, not a neoplasm of the bone.

The tumor-mimicking lesion in the musculoskeletal is defined as a tumor that only looked like a tumor, due to Palpable mass, or radiologic image resembling a tumor (Miller M, 2012). In order to prove it is a true neoplasm, further diagnostic is required.

Knowledge regarding tumor-mimicking lesions will reduce unnecessary procedures (Shimose et al., 2008), relieve the patient's agitation, helps in diagnostic accuracy, and ultimately the proper management (Dirschl \& Almekinders, 1993). Clinical history, underlying diseases, age, trauma, and records of surgery are required in deciding the diagnosis, Choosing the right imaging method is crucial in differentiating tumor-mimicking lesions from neoplasm (Rahardjo P, Utomo SA, 1998). Not rarely, the imaging leads us to believe that non-tumour is a tumor.

\section{CONCLUSION}

The proper selection of an imaging modality is important in differentiating tumor-mimicking lesions from true neoplasms. Pathology will conclude the diagnosis by having representative tissue (Hoch, 2011). Triple Diagnosis by an Orthopaedic Surgeon, the Radiologist, and also the Pathologist will increase the rate of proper diagnosis in difficult cases like tumor mimics.

\section{CONFLICT OF INTEREST}

The authors confirm that there is no conflict of interest regarding the publication of this paper and significant financial support from any company for this work that could have influenced its outcome.

\section{REFERENCES}

Binesh, F., Sobhan, M., Moghadam, R. N., \& Akhavan, A. (2013). Exuberant callus formation misdiagnosed as osteosarcoma: a case report. The ChineseGerman Journal of Clinical Oncology, 12(3), 137-139. https://doi.org/10.1007/ s10330-012-1080-z

Dirschl, D. R., \& Almekinders, L. C. (1993). Osteomyelitis. Drugs, 45(1), 29-43. https://doi.org/10.2165/00003495199345010-00004

Gersch, R. P., Lombardo, F., McGovern, S. C., \& Hadjiargyrou, M. (2005). Reactivation of Hox gene expression during bone 


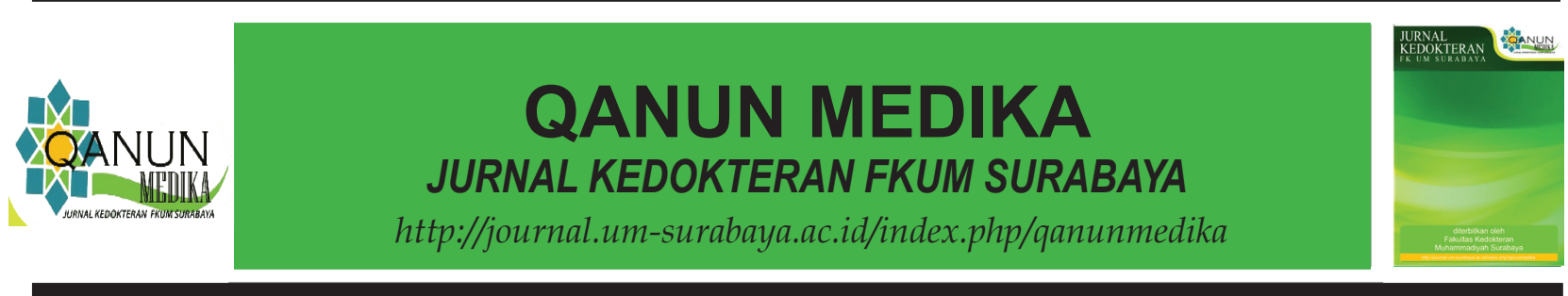

regeneration. Journal of Orthopaedic Research, 23(4), 882-890. https://doi. org/10.1016/j.orthres.2005.02.005

Hoch, B., \& Montag, A. (2011). Reactive bone lesions mimicking neoplasms. Seminars in Diagnostic Pathology, 28(1), 102-112. https://doi.org/10.1053/j. semdp.2011.02.011

Huang, P.-Y., Wu, P.-K., Chen, C.-F., Lee, F.T., Wu, H.-T., Liu, C.-L., ... Chen, W.M. (2013). Osteomyelitis of the femur mimicking bone tumors: a review of 10 cases. World Journal of Surgical Oncology, 11(1), 283. https://doi. org/10.1186/1477-7819-11-283

Kim, S. Y., Park, J. S., Ryu, K. N., Jin, W., \& Park, S. Y. (n.d.). Various tumor-mimicking lesions in the musculoskeletal system: causes and diagnostic approach. Korean Journal of Radiology, 12(2), 220-231. https://doi. org/10.3348/kjr.2011.12.2.220

Madewell, J. E., Ragsdale, B. D., \& Sweet, D. E. (1981). Radiologic and pathologic analysis of solitary bone lesions. Part I: internal margins. Radiologic Clinics of North America, 19(4), 715-748. Retrieved from http://www.ncbi.nlm. nih.gov/pubmed/7323290

Miller M. (2012). Review of Orthopaedics (6th ed.). Virginia: Saunders.

Rahardjo P, Utomo SA. (1998). Imejing Diagnostik Tumor Tulang. In Abdurrahman (Ed.), Penanganan Terpadu Tumor Muskuloskeletal. Surabaya: Universitas Airlangga.

Salter RB. (1999). Textbook of Disorders and Injuries of the Muskuloskeletal Sistem (3rd ed.). Baltimore, MD: Williams \& Wilkins.

Shimose, S., Sugita, T., Kubo, T., Matsuo, T., Nobuto, H., \& Ochi, M. (2008). Differential diagnosis between osteomyelitis and bone tumors. Acta Radiologica, 49(8), 928-933. https://doi. org/10.1080/02841850802241809

Solomon L, Warwick D, N. S. (2010). Apley's System of Orthopaedics and Fractures (9th ed.). London: Hodder Arnold.

Ward WG, Corey RM, Watkins-Castillo SI. (2014). United States Bone and Joint Initiative: The Burden of Muskuloskeletal Diseases in the United States. Rosemont, IL. 